\title{
Uso da Inteligência Competitiva e Tecnológica para Depósito de Patentes e Transferência de Tecnologia em Núcleos de Inovação Tecnológica
}

\section{Competitive Intelligence and Technological Usage for Filing Patents and Transfer of Technology in Technology Transfer Offices}

\author{
Melissa da Silva Carvalho \\ Thiago Borges Renault ${ }^{2}$ \\ ${ }^{1}$ Fundação Oswaldo Cruz e Universidade Federal Rural do Rio de Janeiro, Rio de Janeiro, RJ, Brasil \\ ${ }^{2}$ Universidade Federal Rural do Rio de Janeiro, Rio de Janeiro, RJ, Brasil
}

\begin{abstract}
Resumo
As competências mínimas dos núcleos de inovação tecnológica foram alteradas pela nova lei de inovação em 2016. Entre as mudanças, se insere a necessidade de realizar ações de prospecção e inteligência competitiva. O objetivo deste estudo de caso é descrever e analisar como a área de informação tecnológica de uma instituição de ciência $e$ tecnologia contribui para as atividades do núcleo de inovação tecnológica. O estudo foi realizado analisando os relatórios e atividades da área de informação tecnológica. Conclui-se que as ações de inteligência competitiva implementadas ainda necessitam de aprimoramento para que a informação alcance as principais instâncias de decisão da instituição. Evidencia-se que as ações de inteligência estão restritas à tomada de decisão em relação às atividades de depósito de patentes e de transferência de tecnologia.
\end{abstract}

Palavras-chave: Prospecção. Inteligência competitiva. Núcleo de inovação tecnológica. NIT.

\begin{abstract}
The minimum skills of the technology transfer offices have been changed by the new innovation law in 2016. Among the changes, the increase needing to perform actions of prospecting and competitive intelligence. The objective of this case study is to describe and analyze how the information technology area of an institution of science and technology contributes to the core activities of technological innovation. The study was conducted by analyzing the reports and activities of the information technology area. It is concluded that competitive intelligence actions implemented still need improvement so that the information reaches the main decision makers of the institution. It is evidenced that the actions of intelligence are restricted to decision-making regarding the activities of filing patents and transfer of technology.
\end{abstract}

Keywords: Prospection. Competitive intelligence. Technology transfer office. TTO.

Área tecnológica: Inovação. Gestão. 


\section{Introdução}

O Núcleo de Inovação Tecnológica (NIT) é a estrutura designada pela Lei de inovação para gerir a política de inovação das instituições de ciência e tecnologia. Em 2016, a publicação do novo marco legal, Lei n. 13.243, de 11 de janeiro de 2016, ampliou as competências mínimas atribuídas aos NITs. Entre os itens inseridos no artigo 16, destaca-se o inciso VII que diz respeito ao "[...] desenvolvimento de estudos de prospecção tecnológica e inteligência competitiva no campo da propriedade intelectual, de forma a orientar as ações de inovação da ICT" (BRASIL, 2016, art. 16). No entanto, o relatório Formulário para Informações sobre a Política de Propriedade Intelectual das ICT do Brasil (Formict) ano base 2016 informa que somente 74,8\% das instituições possuem NIT implementado e que apenas $28 \%$ possuem ações de prospecção tecnológica e inteligência competitiva implementadas (BRASIL/MCTIC, 2017).

As instituições de ciência e tecnologia se deparam com uma série de obstáculos para estruturar seus núcleos de inovação tecnológica. Um estudo de Silva e Andrade (2013) com núcleos de inovação tecnológica de instituições públicas de ciência e tecnologia concluiu que os problemas enfrentados por todos eles são semelhantes e, vão desde a falta de infraestrutura física até a inexistência de cultura institucional para inovação. Além disso, Queyras e Quoniam (2006) apontam que atividades de inteligência competitiva não existem ou são pouco exploradas no setor público. As instituições públicas carecem de entendimento de que a inteligência competitiva não é espionagem e que mesmo no setor público é preciso se atentar para os concorrentes e analisar o ambiente interno e externo colaborando para as atividades de inovação (SILVA; ANDRADE, 2013). Assim, estudos nesse tema são importantes para incentivar ações de inteligência competitiva no setor público.

Com ações de prospecção e inteligência competitiva, é possível identificar tecnologias com potencial para transferência e/ou parceiros para desenvolvimento além de estimular o desenvolvimento tecnológico. Etzkowitz (2009) discute em seu trabalho que a implementação de ações de inteligência e transferência de tecnologia dentro das universidades também é um passo importante para a criação de instituições empreendedoras favorecendo assim o desenvolvimento econômico.

Dessa forma, o propósito deste estudo de caso é descrever e analisar como a área de informação tecnológica de uma instituição de ciência e tecnologia contribui para as atividades do núcleo de inovação tecnológica. Para tanto, serão apresentadas e analisadas ações de inteligência competitiva desenvolvidas naquele local.

\section{Inteligência Competitiva e Prospecção Tecnológica}

Inteligência competitiva não é somente um agrupar de informações. Para ser inteligência, essas informações precisam ser coletadas e analisadas de forma que contribuam para a estratégia da organização a curto e longo prazo. Tarapanoff (2006) descreve a inteligência competitiva como uma busca de informações sobre o ambiente seja ele, de fornecedores, de clientes, de parceiros ou de competidores que proporcione uma melhor posição neste mesmo contexto. Gomes e Braga (2004) acrescentam ainda que é um processo ético que possibilita a aplicação das informações no processo decisório nos níveis estratégico e tático das organizações. 
A inteligência competitiva surge com as práticas de inteligência militar e governamental que foram disseminadas para o mundo empresarial. A partir dessa experiência, os empresários, com alguns poucos professores, iniciaram o desenvolvimento do conceito de inteligência se conscientizando para a importância da informação no ambiente de negócios (PRESCOTT; MILLER, 2002).

Para Gomes e Braga (2004), um sistema de inteligência utiliza-se dos dados para obter informação e então transformar em inteligência. Sistemas de inteligência e monitoramento fazem parte dos métodos de prospecção, segundo Coelho (2003). Ele aponta que ações de monitoramento são fundamentais para buscar informação nas quais a prospecção estará baseada. Neste contexto, define prospecção como um tipo de estudo que tem por finalidade obter informações sobre eventos futuros para que a tomada de decisão do presente seja baseada em conhecimento (COELHO, 2003).

Um estudo comparativo de técnicas de prospecção concluiu que monitoramento e sistemas de inteligência são técnicas de maior custo principalmente devido ao valor de acesso às informações mas por outro lado são técnicas que produzem resultados confiáveis (REIS; VINCENZI; PUPO, 2016). As informações são em grande parte de origem privada e o alto custo provem do acesso de bases de dados, como Dialog, Ovid, Questel, entre outras, que agrupam dados científicos, técnicos e de marketing, por exemplo, oferecendo informação atualizada periodicamente (QUEYRAS; QUONIAM, 2006).

Amparo, Ribeiro e Guarieiro (2012) assinalam que os estudos de inteligência competitiva estão relacionados ao processo de prospecção tanto no início, monitorando tecnologias, quanto no fim, indicando áreas para acompanhamento sistemático. Além disso, os autores enfatizam que a prospecção tecnológica se propõe a analisar possíveis mudanças futuras em tecnologias. Mayerhoff (2008, p. 7) define prospecção tecnológica como "[...] um meio sistemático de mapear desenvolvimentos científicos e tecnológicos futuros capazes de influenciar de forma significativa uma indústria, a economia ou a sociedade como um todo".

No entanto, prospecção não está somente relacionada a estados futuros, a análise do estado da arte aborda o histórico e tendências de mercado de determinada tecnologia (AMPARO; RIBEIRO; GUARIEIRO, 2012). Prospecção está relacionada à busca de informação com o intuito de encontrar algo novo que seja relevante para a organização e sua missão (TEIXEIRA; SOUZA, 2013). Assim, ambos os termos, inteligência e prospecção, podem ser aplicados a estudos que enfatizem tanto o momento atual quanto as tendências futuras, e que acrescentem valor a organização.

Teixeira e Valentim (2016) compilaram em seus estudos as diversas fases para ações de inteligência competitiva, porém, os autores destacam quatro que são as mais comuns. A primeira diz respeito à definição do objetivo da informação. Nessa fase, é preciso identificar quais questões serão respondidas, ou seja, qual é a necessidade dos decisores (GOMES; BRAGA, 2004; PRESCOTT; MILLER, 2002). 
Na segunda fase efetua-se a coleta de dados. As fontes de informação para ações de inteligência competitiva são inúmeras: artigos científicos, documentos de patente, normas, relatórios de congressos e bases de dados que agrupam informações diversas (QUEYRAS; QUONIAM, 2006). Entretanto, nem sempre a informação de que se necessita está facilmente disponível sendo interessante consultar a rede de colaboradores e contatos dentro e fora da organização (GOMES; BRAGA, 2004). Indivíduos fornecem informações que não estão disponíveis formalmente. Uma rede de contato, seja ela de colaboradores internos ou externos à organização, é valiosa para transferir esse conhecimento tácito ou ainda identificar outras possíveis fontes para se obter as informações desejadas (PRESCOTT; MILLER 2002; GOMES BRAGA 2004).

A terceira fase é a análise dos dados. Nessa etapa, a qualificação dos analistas é essencial e o profissional se utiliza de várias habilidades e conhecimentos para pesquisar, analisar e até propor sugestões e considerações para os gestores responsáveis pela tomada de decisão (LANA, 2011). São os indivíduos da organização que atribuem sentido à informação de forma que ela seja usada no processo decisório (TEIXEIRA; VALENTIM, 2016). Podem ser utilizadas diversas metodologias para análise das informações brutas, como modelo das cinco forças de Porter para avaliação do ambiente competitivo ou análise SWOT, entre outras, avaliando a posição da organização frente aos concorrentes (GOMES; BRAGA, 2004).

Por último, é preciso disseminar a informação. Teixeira e Valentim (2016) enfatizam que para que a informação se transforme em inteligência se faz necessário o compartilhamento das informações com os responsáveis pela tomada de decisão, a fim de que essas informações sejam utilizadas em ações estratégicas da organização. Cabe ao analista a decisão de qual é a melhor forma de disseminação, seja por relatórios completos seja por resumos executivos, utilizando ou não formas gráficas e visualmente atrativas (LANA, 2011). A disseminação pode ser feita para toda a organização ou focar em um usuário ou grupo de usuários (GOMES; BRAGA, 2004).

Em resumo, inicialmente é preciso definir as necessidades da informação e a quem ela interessa. Após definição do propósito, selecionam-se as fontes de informação para a coleta de dados. Entre inúmeras fontes, destacam-se os documentos de patente que fornecem diversas informações a respeito de mercado e desenvolvimento tecnológico. O documento de patente pode revelar conhecimento legal, técnico e de mercado que permite acompanhar tendências e concorrentes. Também é importante para identificar macro e micro ambiente, empresas e inventores de tecnologias auxiliando os núcleos de inovação tecnológica a desenvolverem sua missão (TEIXEIRA; SOUZA, 2013). Por fim, realiza-se a análise e disseminação das informações para os responsáveis pela decisão.

A Figura 1 resume as principais fases da inteligência competitiva e sua relação com os métodos de prospecção. A importância da informação contida em documentos de patente será tratada na seção seguinte. 
Figura 1 - Prospecção, Inteligência tecnológica e suas etapas

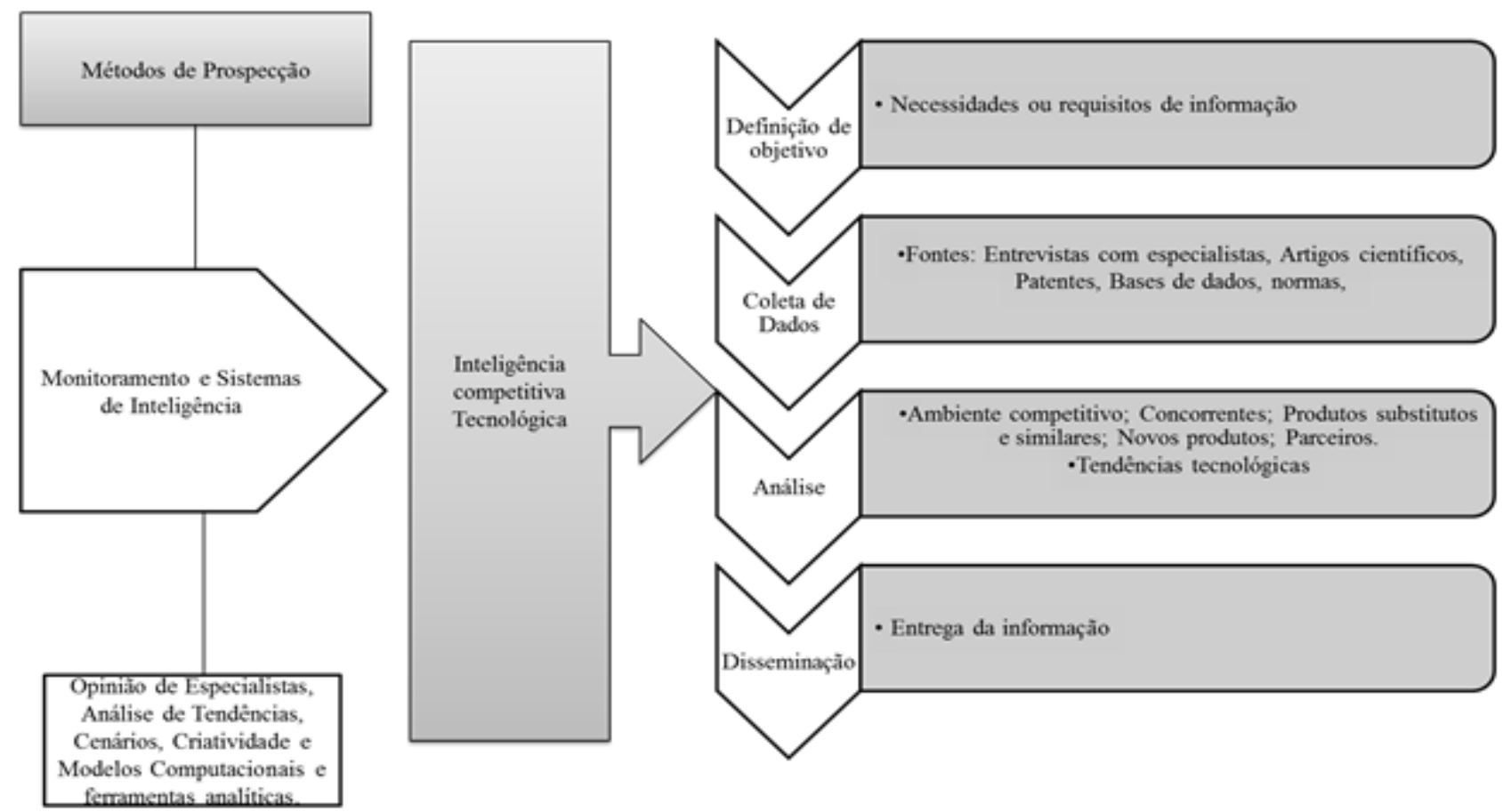

Fonte: Elaborada pelos autores deste artigo

\section{Importância da Informação de Patentes}

Em ambientes altamente competitivos, como os do setor de ciências da vida em que um produto leva em torno de 20 anos para ser lançado (CGEE, 2017), os inventores têm que se armar de mecanismos de proteção, como segredo industrial e direitos de propriedade, que favoreçam todo o investimento considerando os altos custos e riscos do desenvolvimento. O depósito de pedido de patente é um desses mecanismos e a atividade do núcleo de inovação está intimamente ligada a ela.

Propriedade intelectual diz respeito a criações da mente, como invenções; obras literárias e artísticas; desenhos; e símbolos, nomes e imagens utilizados no comércio, ou seja, se referem a criações do espírito humano. É dividida em: direto de autor e conexos (direitos concedidos a autores de obras intelectuais), propriedade industrial e direito sui generis (o que não é considerado direito do autor ou propriedade industrial tais como conhecimentos tradicionais etc.) (JUNGMANN; BONETTI, 2010).

A propriedade industrial se refere a direitos concedidos e pode ser do tipo: marca, patente, desenho industrial, indicação geográfica e repressão à concorrência desleal. Uma patente é um título de propriedade temporário outorgado pelo Estado aos inventores detentores de direitos sobre a criação. Portanto, a patente protege uma invenção e garante ao titular dessa invenção o direito exclusivo de utilizar a sua invenção (OMPI/INPI, 2015a). Uma patente de invenção representa uma solução nova para um problema existente dentro de determinado campo tecnológico. Já o modelo de utilidade refere-se a uma criação de um objeto de uso prático que apresente nova forma ou disposição, envolvendo ato inventivo, que resulte em funções de uso ou fabricação melhoradas (INPI, 2013). 
Para que um produto seja patenteável, ele deve cumprir três critérios simultaneamente: possuir atividade inventiva, aplicação industrial e novidade. A invenção não pode ter sido divulgada previamente, ser evidente ou óbvia de tudo aquilo que já foi disponibilizado de conhecimento anteriormente, além de poder ser produzida industrialmente (BRASIL, 1996; INPI, 2013).

As vantagens de se possuir uma patente giram em torno de que esse documento confere direitos exclusivos que permitem que o titular utilize e explore a invenção, permitem também que o titular conquiste posições de mercado vantajosas, uma vez que impede outros de comercializarem o produto em torno de 20 anos; recompensa o inventor estimulando novas invenções e ainda estimula os concorrentes a buscarem soluções alternativas para o problema (INPI, 2013; OMPI/INPI, 2015a).

Além de todas as vantagens mencionadas anteriormente, a patente também é um grande instrumento de informação tecnológica. Por meio da patente, tecnologias que antes estariam protegidas por segredo industrial são disponibilizadas para a sociedade. No mais, a informação técnica atualizada e detalhada é disponibilizada antes mesmo de o produto estar no mercado. Estima-se que $70 \%$ das informações publicadas neste documento não foram publicadas em nenhum outro meio e dois milhões de documentos são adicionados todos os anos nas bases de patentes (FENG; ZHAO, 2015; OMPI/INPI, 2015b). Por essa razão, as informações disponibilizadas em documentos de patente são importantes fontes de dados para inteligência competitiva. Para Mayerhoff (2008), o sistema de patentes é importante para estudos de prospecção tecnológica, pois as bases de dados que disponibilizam as informações patentárias são alimentadas continuamente.

Em geral, um documento de patente possui os seguintes campos que devem ser considerados neste trabalho: reivindicações, título, resumo, depositante, inventores, datas e países de depósito e publicação. Além disso, tem-se também a classificação internacional de patentes IPC que é, segundo o INPI, uma ferramenta de busca que classifica os documentos de patente em áreas tecnológicas servindo como parâmetro para a recuperação dos documentos (INPI, 2013).

A facilidade de conseguir os dados de patentes nos escritórios oficiais torna seu uso útil e conveniente para: planejar pesquisa e desenvolvimento, analisar competidores e analisar o ciclo de vida de uma tecnologia, ou seja, como ela nasce, amadurece e desaparece. A combinação das tendências nas publicações e o conhecimento escondido no documento subsidiam os gestores com conhecimento e compreensão dos avanços tecnológicos em suas diversas dimensões para uma melhor tomada de decisão (CHEN et al., 2015).

No entanto, a mineração dos dados obtidos gratuitamente nos escritórios não é tão simples. Em muitos casos, os títulos das patentes não revelam claramente o objeto e, dessa forma, a identificação das informações fica comprometida. Algumas bases de dados reescrevem esses títulos e resumos facilitando a recuperação das informações, porém o custo envolvido é elevado (MA; PORTER, 2015). Também existem ferramentas bibliográficas que disponibilizam informações de citações, depositantes, inventores e classificação IPC enquanto algumas bases de conteúdo incluem desenhos, resumos e reivindicações (PARK et al., 2013). 


\section{Núcleo de Inovação Tecnológica e Área de Informação da Fiocruz}

A Fundação Oswaldo Cruz (Fiocruz) foi fundada em maio de 1900, sendo responsável, à época, por fornecer soros e vacinas para os estados e municípios. Em 1970, passou a fundação pública de direito público sendo atualmente vinculada ao Ministério da Saúde (MS) com o objetivo de produzir, disseminar e compartilhar conhecimentos e tecnologias voltados ao Sistema Único de Saúde (SUS). É composta de 16 unidades técnico-científicas, sendo cinco dessas localizadas fora do estado do Rio de Janeiro nas cidades de Belo Horizonte, Curitiba, Manaus, Recife e Salvador. Em algumas regiões possui escritórios que são unidades que estão em construção de infraestrutura ou, ainda, que, mesmo sem sede, atuam em parceria com universidade e institutos de pesquisa locais (FIOCRUZ/DIPLAN, 2017).

A Coordenação de Gestão Tecnológica (GESTEC) foi estabelecida em 1990 para assessorar a presidência da Fiocruz no que concerne à proteção do patrimônio científico e tecnológico e suas atribuições estão relacionadas à coordenação, planejamento e execução de atividades que dizem respeito à gestão da propriedade intelectual, informação tecnológica e transferência de tecnologia. (EMERICK, 2004; FIOCRUZ/GESTEC, 2018).

O núcleo central de inovação tecnológica da Fiocruz possui uma configuração de sistema denominada Sistema Gestec-NIT. Esse núcleo se constitui de uma coordenação realizada pela Gestec e por núcleos de inovação tecnológica em cada unidade. Possui 20 núcleos de inovação tecnológica implementados sendo um em cada unidade técnico-científica e alguns escritórios para os quais são atribuídas competências de interação mais direta com os pesquisadores. A gestão do Sistema Gestec- NIT é realizada por uma instância colegiada denominada Comitê Gestor do Sistema Fiocruz de Gestão e Inovação - Sistema Gestec-NIT. Esse comitê gestor é formado por um representante de cada área da Gestec e um representante de cada NIT localizado nas Unidades; e se reúne quatro vezes ao ano para discussões, deliberações, planejamento e apresentações sobre temas relacionados à gestão da inovação (FIOCRUZ/GESTEC, 2018).

A Gestec em si é constituída de três grandes áreas internas: Patentes, Informação Tecnológica e Transferência de Tecnologia. A área de Patentes desenvolve atividades de assessoramento de todos os profissionais no que tange à proteção por meio de patentes tanto no Brasil quanto no exterior e gerencia a Comissão de Propriedade Industrial (COPAT). A COPAT é a instância de deliberação sobre o depósito de patentes. A área de transferência de tecnologia assessora e conduz negociações, celebra acordos e contratos relativos à inovação, realiza proteção de marcas, programas de computador e obras autorais e, ainda, assessora sobre acesso ao patrimônio genético.

Por fim, a área de informação tecnológica atua no âmbito da inteligência competitiva. Conta com três analistas: dois biólogos e um farmacêutico e administrador, especializados também em áreas de informação, saúde pública e gestão. 


\section{Metodologia}

Este é um estudo conduzido de forma qualitativa já que se trata de um estudo de caso que busca examinar um fenômeno dentro de seu contexto (ROESCH, 2005) e estudar fenômenos contemporâneos (YIN, 2005). Foi realizada pesquisa documental e bibliográfica. A pesquisa documental é semelhante à pesquisa bibliográfica, no entanto, se diferencia por utilizar materiais sem tratamento analítico (GIL, 2002), por exemplo, registros, memorandos, regulamentos, entre outros (VERGARA, 1998). Além disso, foi utilizado também como método de coleta de dados, a observação. A observação não estruturada permite descrição e explicação de forma informal e espontânea. No mais, trata-se de observação participante na qual a observadora vive o dia a dia da rotina estudada (VERGARA, 2009).

A pesquisa documental foi realizada nos documentos de gestão, como procedimentos operacionais utilizados na Gestec e os relatórios de prospecção tecnológica elaborados pela área de informação tecnológica da Gestec. A pesquisa se limitou aos relatórios emitidos no ano de 2016.

A análise considerou os demandantes ou os interesses da prospecção, a forma de coleta de dados e a análise e disseminação da informação. Para avaliação dos demandantes e interesses da prospecção, foi considerada a origem das solicitações e a finalidade da prospecção. Para a forma de coleta de dados e as formas de análise, observou-se a origem das informações $e$ ferramentas utilizadas.

Foram consideradas na avaliação as principais informações extraídas de documentos de patentes e decorrentes de outras fontes que são consideradas na inteligência competitiva $e$ tecnológica, como depositantes de documentos de patente, classificação IPC, fornecedores e consumidores da tecnologia, citações de patentes, ano de depósito, países de publicação e depósito, produtos substitutos e entrantes no mercado e bases de dados utilizadas.

\section{Resultados e Discussão}

A partir da análise documental foram identificados procedimento e guia para a realização das atividades. Na realização das buscas os profissionais da área utilizam procedimentos operacionais que dão diretrizes de execução e utilizam bases de dados para recuperação e tratamento das informações. A Figura 2 ilustra as etapas consideradas no Guia de Busca de Informação Tecnológica (FIOCRUZ/GESTEC, 2017) que fornece diretrizes para realização das buscas visando a atender aos requisitos do relatório da área. 
Figura 2 - Etapas para desenvolvimento de buscas

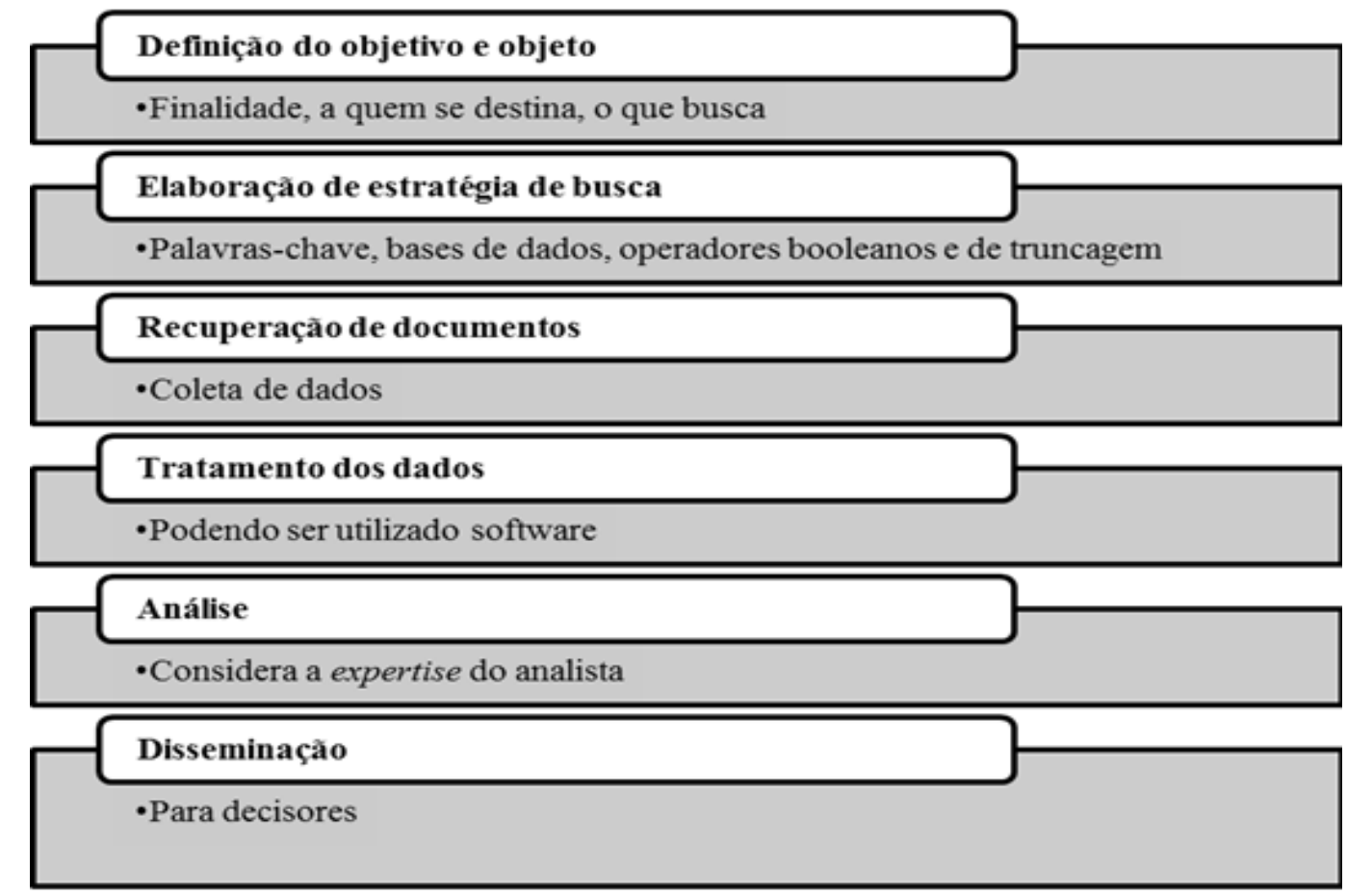

Fonte: Fiocruz/Gestec (2017)

Em 2016, a área de informação tecnológica atendeu 50 solicitações de serviços de diversos demandantes internos da instituição. A partir das solicitações registradas, foram identificados 10 relatórios de prospecção técnica, 35 de prospecção de mercado e cinco de prospecção de empresas.

Os trabalhos são classificados internamente como: prospecções técnicas, que são todas as buscas realizadas para subsidiar a pesquisa e desenvolvimento com vistas a identificar rotas científicas e tecnológicas. As prospecções de indústria objetivam identificar parceiros e/ou concorrentes e as de mercado e produto são realizadas para identificar produtos, potenciais produtores e consumidores (FIOCRUZ/GESTEC, 2016). Todos esses tipos se adequam ao conceito de inteligência competitiva tecnológica apresentado no referencial teórico.

As principais bases de dados utilizadas para recuperar informação contida nos relatórios analisados são as dos escritórios oficiais de propriedade industrial e bases disponíveis com acesso via Portal Capes que são gratuitas para instituições públicas. As bases mais utilizadas no portal Capes são Thomson Integrity, Derwent Innovations Index, Scielo e Scifinder. Além disso, está disponibilizada para uso a base comercial com informações de patentes Questel Orbit. Segundo Mayerhoff (2008), as bases comerciais e alguns softwares se diferem das bases gratuitas no que diz respeito ao tratamento dos dados. $\mathrm{O}$ uso dessas bases agiliza o processo de tratamento de dados quando comparados com as bases gratuitas. Isso ocorre porque as bases comerciais dispõem de ferramentas que automatizam etapas. Porém, essas bases só fornecem a análise quantitativa e não substituem a capacidade humana de atribuir significado aos gráficos e tabelas fornecidos (GOMES; BRAGA, 2004). Dessa forma, a análise qualitativa, como menciona Teixeira e Souza (2013), precisa ser realizada por profissionais capacitados que conheçam os objetivos da instituição e da informação.

Em relação às demandas, estas são originadas principalmente pelos NITs e pela área de patentes da própria Gestec. A área de patentes é responsável pela realização de estudo de 
viabilidade patentária de invenções e acompanha a tramitação perante órgãos de propriedade industrial. Além disso, a área de patentes gerencia a Comissão de propriedade industrial (COPAT). Os NITs possuem relação direta com o pesquisador, porém, poucas buscas são demandadas pelos NITs para a Gestec e poucas buscas são realizadas pelos próprios NITs. Uma pesquisa realizada em uma universidade da China apresentou que metade dos pesquisadores entrevistados informou que só realizava buscas em base de patentes quando precisava submeter o projeto para elaboração de patentes (FENG; ZHAO, 2015). Buscar informações na etapa de projeto é importante, pois, segundo Teixeira e Souza (2013), as informações contidas em patentes não estão disponibilizadas em outros locais. Além disso, as informações permitem que o pesquisador não reinvente a roda. Assim, realizar buscas em fase anterior ao depósito, ou seja, ainda, no planejamento da pesquisa, pode cooperar para a aceleração do depósito e até mesmo da própria pesquisa, visto que o pesquisador pode analisar o que já está no estado da arte dentro de sua área de estudo. Dessa forma, existe uma lacuna no canal de comunicação entre pesquisador, NIT e Gestec. A pouca demanda dos NITs para levantamento de informações sobre projetos de pesquisa de sua unidade demonstra que possivelmente os projetos não estão sendo acompanhados desde a sua concepção.

Outro ponto observado diz respeito aos assuntos tratados na área. Os assuntos de busca que são demandados transitam nos mais diversos conteúdos. Essa diversidade dificultou uma classificação por tema. A Fiocruz atua em diversos segmentos da área de saúde, o que leva a uma gama de assuntos que vão desde biotecnologia, diagnósticos diversos a produtos médicos hospitalares. Contudo, após análise dos documentos foi realizado o agrupamento de acordo com a finalidade do relatório baseado nos seus objetivos e no cliente a que ele se destina. Os objetivos principais encontrados foram:

a)Subsidiar decisões de reuniões da Comissão de propriedade intelectual quanto a depósito nacional, internacional, manutenção e entrada como cotitular de depósito de patente em parceria com outras instituições.

b)Subsidiar desenvolvimento de pesquisas.

c) Subsidiar reuniões de transferência de tecnologia ou acordos de cooperação.

d)Atender a necessidades estratégicas da coordenação e da presidência da instituição.

Desse modo, após análise, os relatórios foram agrupados quantitativamente da seguinte forma:

Tabela 1 - Percentual de relatórios elaborados segundo finalidade

\begin{tabular}{lc}
\multicolumn{1}{c}{$\quad$ FinALIDADE } & $\%$ \\
Subsídio a depósito internacional & $14 \%$ \\
Subsídio a depósito nacional & $24 \%$ \\
Subsídio a desenvolvimento de pesquisa & $18 \%$ \\
Atender necessidades estratégicas institucionais & $8 \%$ \\
Subsidiar decisão de manutenção/abandono de patente & $20 \%$ \\
Subsidiar reuniões de negociação e acordos de cooperação ou parcerias & $16 \%$ \\
\hline
\end{tabular}

Fonte: Elaborada pelos autores deste artigo 
Tomando como base o conteúdo dos relatórios, foi observado que estes não contêm somente informações extraídas de documentos de patente, mas também informações epidemiológicas e de artigos científicos em que se apontam os possíveis territórios consumidores, abrangência de mercado e tendências tecnológicas. Além disso, contém informações sobre territórios de depósito e territórios de publicação de patentes, principais atuantes no mercado que possuem patentes, atuantes no mercado por meio de produtos similares, identificação de possíveis parceiros ou concorrentes nacionais e internacionais.

Em relação aos relatórios desenvolvidos para subsidiar negociações ou acordos de cooperação, as informações ali identificadas abrangem produtos comercializados pela empresa, sua segmentação de mercado, identificação de clientes, além de informações legais, como licenças e registro de produtos. Para subsídio ao depósito internacional são avaliados possíveis parceiros e territórios. Isso otimiza recursos realizando proteção em territórios pertinentes. Em geral, o próprio pesquisador já indica territórios que são, então, validados ou discutidos à luz das informações disseminadas. Todas as informações são utilizadas na tomada de decisão, seja no âmbito da COPAT para depositar ou não os pedidos, seja em negociações ou busca de parcerias para continuidade. Assim, pode-se observar que os relatórios informam os competidores e fornecedores atuais de tecnologias similares. $\mathrm{O}$ acompanhamento sistemático de potenciais entrantes, concorrentes e fornecedores fazem parte do processo de inteligência competitiva (MENDES; ANTUNES, 2003).

No entanto, como evidenciado na análise por finalidade, o uso da informação pela alta direção é limitado. As ações de inteligência estão restritas à tomada de decisão em relação a ações para depósito de patentes e transferência de tecnologia. Uma oportunidade de melhoria é a implementação de monitoramento de tecnologias e análise de parcerias por meio de citações e evolução da patente. No estudo realizado na China, o monitoramento é realizado a cada três meses e usa a mesma estratégia de busca utilizada na busca original (FENG; ZHAO, 2015). Para Teixeira e Souza (2013), o monitoramento é uma continuidade das atividades de prospecção já que visa a acompanhar as informações e os conhecimentos sobre concorrentes, desenvolvimento tecnológico e produtos, entre outros, para orientar a empresa.

\section{Considerações Finais}

Com o novo marco legal, as competências mínimas dos núcleos de inovação tecnológica foram ampliadas. Umas das novas atividades é a implementação de ações de prospecção e inteligência competitiva. Porém, não é uma tarefa simples, visto que $28 \%$ dos NITs apontados no Formict no ano base 2016 possuem essas ações implementadas (BRASIL/MCTIC, 2017). A Fiocruz possui em seu NIT uma área destinada a essas ações. Assim, este estudo teve como pretensão descrever quais ações de inteligência competitiva vêm sendo realizadas pelo núcleo de inovação tecnológica da Fiocruz. Conclui-se que existem ações de inteligência competitiva sendo desenvolvidas principalmente no que tange à gestão de patentes e transferência de tecnologia. Essas ações contribuem para a identificação de parceiros, decisões de depósitos de patente no país ou exterior assim como os territórios para validação dos pedidos de patente. Entretanto, as ações desenvolvidas pelo NIT e pela Gestec alcançam timidamente o desenvolvimento de pesquisas e estratégias da alta direção. Dessa forma, há que se pensar em ações 
que divulguem este trabalho para as áreas relacionadas à pesquisa, contribuindo para a gestão da inovação na instituição.

\section{Referências}

AMPARO, K. K. dos S.; RIBEIRO, M. do C. O.; GUARIEIRO, L. L. N. Estudo de caso utilizando mapeamento de prospecção tecnológica como principal ferramenta de busca científica.

Perspectivas em Ciência da Informação, [S.1.], v. 17, n. 4, p. 195-209, dez. 2012.

BRASIL/MCTIC. Política de Propriedade Intelectual das Instituições Científicas e

Tecnológicas do Brasil - Relatório FORMICT Ano base 2016. Brasília, 2017. Disponível em: https:/www.mctic.gov.br/mctic/export/sites/institucional/tecnologia/propriedade_intelectual/arquivos/ Relatorio-Formict-Ano-Base-2016.pdf. Acesso em: 15 dez. 2017.

BRASIL. Lei n. 9.279, de 14 de maio de 1996. Regula direitos e obrigações relativos à propriedade industrial. [1996]. Disponível em: https://www.planalto.gov.br/ccivil_03/leis/19279.htm. Acesso em: 15 dez. 2017.

BRASIL. Lei n. 13.243, de 11 de Janeiro de 2016. Dispõe sobre os estímulos ao desenvolvimento científico, à pesquisa, à capacitação científica e à inovação e altera leis nos termos da Emenda Constitucional n85 de 26 de fevereiro de 2015. [2016]. Disponível em: http://www.planalto. gov.br/ccivil_03/_Ato2015-2018/2016/Lei/L13243.htm. Acesso em: 15 jan. 2018.

\section{CGEE - CENTRO DE GESTÃO E ESTUDOS ESTRATÉGICOS. Competências para inovar na} indústria farmacêutica brasileira. Brasília: CGEE, 2017.

CHEN, H. et al. A patent time series processing component for technology intelligence by trend identification functionality. Neural Comput \& Applic, [S.I.], v. 26, p. 345-353, 2015.

COELHO, G. Nota Técnica - 14 Prospecção Tecnológica: Metodologias e Experiências Nacionais e Internacionais. Projeto CTPetro Tendências Tecnológicas, [S.I.], p. 105, 2003.

EMERICK, M. C. Gestão tecnológica como instrumento para a promoção do desenvolvimento econômico-social: uma proposta para a Fiocruz. 2004. Dissertação (Mestrado em Gestão de C\&T em Saúde) - Escola Nacional de Saúde Pública ENSP/Fiocruz, 2004.

ETZKOWITZ, H. Hélice Tríplice Universidade-Indústria-Governo. Porto Alegre: EDIPUCRS, 2009.

FENG, J.; ZHAO, N. The Journal of Academic Librarianship A New Role of Chinese Academic Librarians - The Development of Embedded Patent Information Services at Nanjing Technology University Library, China. The Journal of Academic Librarianship, [S.l.], v. 41, n. 3, p. 292-300, 2015.

FIOCRUZ/DIPLAN. Relatório de Gestão Fiocruz 2016. 1. ed. Rio de Janeiro: Fiocruz/Diplan, 2017.

FIOCRUZ/GESTEC. Procedimento Operacional Padrão Gestec IT001 Busca de Informação Tecnológica. 1. ed. Rio de Janeiro: Fiocruz/Gestec, 2016.

FIOCRUZ/GESTEC. Guia de Busca de Informação Tecnológica. 1. ed. Rio de Janeiro: Fiocruz/ Gestec, 2017. 
FIOCRUZ/GESTEC. Portal Gestec. [2018]. Disponível em: http://www.fiocruz.br/vppis/gestec/. Acesso em: 21 jan. 2018.

GIL, A. C. Como elaborar projetos de pesquisa. 4. ed. São Paulo: Atlas, 2002.

GOMES, E.; BRAGA, F. Inteligência competitiva: como transformar informação em um negócio lucrativo. 2. ed. Rio de Janeiro: Elsevier, 2004.

INPI - INSTITUTO NACIONAL DA PROPRIEDADE INDUSTRIAL. Inventando o futuro: uma introdução às patentes para as pequenas e medias empresas. 1. ed. Rio de Janeiro: Instituto Nacional da Propriedade Industrial, 2013.

JUNGMANN, D. de M.; BONETTI, E. A. A caminho da inovação: proteção e negócios com bens de propriedade intelectual: guia para o empresário. 1. ed. Brasília, DF: IEL, 2010.

LANA, R. A. Inteligência Competitiva: fator-chave para o sucesso das organizações no novo milênio. Revista Inteligência Competitiva, [S.l.], v. 1, n. 3, p. 305-327, 2011.

MA, J.; PORTER, A. L. Analyzing patent topical information to identify technology pathways and potential opportunities. Scientometrics, [S.l.], v. 102, n. 1, p. 811-827, 2015.

MAYERHOFF, Z. D. V. L. Uma Análise Sobre os Estudos de Prospecção Tecnológica. Cadernos de Prospecção, Salvador, v. 1, n. 1, p. 7-9, 2008.

MENDES, C. da C.; ANTUNES, A. M. de S. Inteligência Tecnológica: variáveis para monitoramento do ambiente externo em instituições de pesquisa tecnológica. Banco de artigos técnicos INMETRO, [S.I.], 2003.

OMPI/INPI - ORGANIZAÇÃO MUNDIAL DE PROPRIEDADE INTELECTUAL/INSTITUTO NACIONAL DA PROPRIEDADE INDUSTRIAL. Curso geral de propriedade intelectual DL101PBR Módulo Patentes. Apostila de Curso. 1. ed. 2015: OMPI/INPI, 2015a.

OMPI/INPI - ORGANIZAÇÃO MUNDIAL DE PROPRIEDADE INTELECTUAL/INSTITUTO NACIONAL DA PROPRIEDADE INDUSTRIAL. Curso geral de propriedade intelectual DL101PBRMódulo Informação Tecnológica. In: OMPI/INPI - Organização Mundial de Propriedade Intelectual/ Instituto Nacional da Propriedade Industrial. Apostila de Curso. 1. ed. OMPI/INPI, 2015 b.

PARK, H. et al. A patent intelligence system for strategic technology planning. Expert Systems with Applications, [S.l.], v. 40, n. 7, p. 2.373-2.390, 2013.

PRESCOTT, J. E.; MILLER, S. H. Inteligência competitiva na prática: técnicas e práticas bem sucedidas para conquistar mercados. Rio de Janeiro: Campus, 2002.

QUEYRAS, J.; QUONIAM, L. Inteligência competitiva. In: TARAPANOFF, Kira. (org.). Inteligência, informação e conhecimento em corporações. Brasília, DF: IBICT, UNESCO, 2006. p. 73-98.

REIS, D. R. dos; VINCENZI, T. B. de; PUPO, F. P. Técnicas de Prospecção: um Estudo Comparativo. Revista de Administração Contemporânea, [S.l.], v. 20, n. 2, p. 135-153, 2016.

ROESCH, S. M. A. Projetos de Estágios e de Pesquisa em Administração. São Paulo: Atlas, 2005.

SILVA, A. M. da; ANDRADE, E. P. de. Inteligência Competitiva e Gestão por Competência como Horizonte de Ação para os Núcleos de Inovação Tecnológica em Instituições Públicas de Ciência e Tecnologia. In: ENCONTRO DA ANPAD - ENANPAD, 37, Anais [...], p. 1-16, 2013. 
TARAPANOFF, K. Informação, Conhecimento e Inteligência em Corporações: relações e complementaridade. In: TARAPANOFF, Kira. (org.). Inteligência, informação e conhecimento em corporações. Brasília, DF: IBICT, UNESCO, 2006. p. 73-98.

TEIXEIRA, R. C.; SOUZA, R. R. O uso das informações contidas em documentos de patentes nas práticas de Inteligência Competitiva : apresentação de um estudo das patentes da UFMG.

Perspectivas em Ciência da Informação, [S.I.], v. 18, n. 1, p. 106-125, 2013.

TEIXEIRA, T. M. C.; VALENTIM, M. L. P. Inteligência competitiva Organizacional: Um estudo teórico. Perspectivas em Gestão \& Conhecimento, [S.l.], v. 6, Número Especial, p. 3-15, 2016.

VERGARA, S. Projetos e relatórios de pesquisa em administração. 2. ed. São Paulo: Atlas, 1998.

VERGARA, S. Metodos de coleta de dados no campo. 1. ed. São Paulo: Atlas, 2009.

YIN, R. Estudo de caso: planejamento e métodos. 3. ed. Porto Alegre: Bookman, 2005.

\section{Sobre os Autores}

\section{Melissa da Silva Carvalho}

E-mail:melissinhasc@yahoo.com.br Mestre em Gestão e Estratégia/UFRRJ

Endereço profissional: Av. Brasil, n. 4.036, Maré, Rio de Janeiro, RJ. CEP: 21040-361.

\section{Thiago Borges Renault}

E-mail: thiagorenault@ufrrj.br

Doutor em Engenharia de Produção pela COPPE/UFRJ

Endereço profissional: Rod. BR 465, Km 7, Seropédica, RJ, ICSA/DCAd/S.14. CEP: 23897-000. 